\section{Drusen classification in bilateral drusen and fellow eye of exudative age- related macular degeneration}

S Hamada, S Jain, V Sivagnanavel, N Patel and NV Chong

\begin{abstract}
Aim To assess the value of the modified international classification system in screening high-risk patients with bilateral age-related maculopathy (ARM) from those with lower risk characteristics.

Methods In total, 164 digital images of 106 patients with either bilateral ARM (group A) or the fellow eyes of unilateral exudative age-related macular degeneration (AMD) (Group B) were included. Patients with no signs of ARM in both eyes or those with bilateral late AMD were excluded.
\end{abstract} The images were randomised and then graded by two masked ophthalmologists based on the modified International Classification of ARM.

Results The interobserver consistency between the two graders was high with a Kappa value of 0.82 (SE $0.34, P<0.0001$ ). There were no significant differences in the distribution of the stages of ARM between the two subgroups. Stage 3 was the most common stage in each group for both graders followed by stage $2 a$ in the bilateral drusen group. Stages $1 a, 2 a$ and $2 b$ were equally the next common stage in the fellow eye of chordial neovascularisation group.

Conclusion A screening system based on clinical characteristics would be of value in risk prediction in a clinical setting. Type of Drusen alone, as identified by the modified International grading system, may not be reliably predictive in screening for patients who are at high risk of developing choroidal neovascularisation.

Eye (2006) 20, 199-202. doi:10.1038/sj.eye.6701852; published online 4 March 2005

\section{Introduction}

Choroidal neovascularisation (CNV) is the leading cause of blindness in the developed world. For persons aged 75 years or older, age-related macular degeneration (AMD) is the major cause of the increased prevalence of blindness. ${ }^{1,2}$ The overall 2-year cumulative incidence of AMD in Rotterdam study was $0.2 \%$, increasing to $1.8 \%$ in subjects of 85 years or older. This is lower than the incidence rate in the United States. ${ }^{1}$ The prevalence in UK was about $1.64 \%$ of population (Melton Mowbray study). ${ }^{3}$ In one of the recent studies, it is estimated that in Britain there are 172000 and 245000 cases with geographical and neovascular AMD, respectively. ${ }^{4}$ The relative risk in AMD as a function of early-age related maculopathy (ARM) fundus signs has been described in various studies. ${ }^{5-9}$ The International ARM Epidemiological Study Group has described an international classification and grading system for ARM and AMD. ${ }^{10}$ This was followed by the Rotterdam study, a population-based prospective cohort study, which described stepwise progression of ARM. ${ }^{11,12}$

The reliability of the current method of the modified international classification of ARM in screening for patients at high risk of developing $\mathrm{CNV}$ is still unclear. In this study, we compared the staging of disease in patients with bilateral ARM against the staging of ARM in the fellow eye of patients with unilateral exudative AMD. The aim was to identify if the modified international grading system could be used to differentiate between patients with a relatively low risk of visual loss (bilateral drusen subgroup) and those with a much higher risk of visual loss (fellow eye subgroup).
Retinal Research Unit, King's College Hospital, University of London, UK

Correspondence: NV Chong King's College Hospital, Retinal Research Unit, Normandy Building, Denmark Hill, London SE5 9RS, UK Tel: + 442073464548 ; Fax: +442073463738 E-mail: victor@ eretina.org

Received: 18 September 2004

Accepted: 5 January 2005 Publised online: 4 March 2005 


\section{Methods}

Colour fundus images (Topcon TRC 50IX retinal camera) of consecutive patients referred to the Retinal Research Unit at King's College Hospital, London, between December 2002 and December 2003 were reviewed. All images were centred on the macula and were of good quality $\left(50^{\circ}\right.$ field). The inclusion criteria consisted of patients with bilateral ARM (drusen in both eyes) and fellow eye of patients with unilateral exudative AMD. We excluded all patients with no signs of ARM in both eyes and those with bilateral neovascular disease or advanced atrophy. Patients with ocular comorbidity from diseases other than AMD such as diabetes were also excluded. The selected images were randomised by an independent investigator and then graded by two ophthalmologists, independent of each other, using the modified International Classification of ARM (Figure 1). ${ }^{10-12}$ Graders were masked to the patient diagnosis. Discrepancies between the two graders were resolved by a third expert grader. The distribution of each stage of ARM within the two study subgroups was calculated as percentages. $\chi^{2}$ linear correlation testing was used to identify the significance of the distribution of the disease stages between the two patient subgroups. The interobserver variability of the graders was assessed using the Kappa statistical method.

\section{Results}

After excluding images of poor quality, a total of 164 images, of 106 patients, were considered suitable for inclusion. These were divided into two groups:

Group A = bilateral ARM (drusen/drusen) group, which included 133 images.

Group B = fellow eye of exudative AMD (drusen/ $\mathrm{CNV}$ ) group which involved 31 images.

The interobserver consistency between the two graders was high with a Kappa value of 0.82 (SE 0.34, $P<0.0001$ ). The distribution of stages within each group is illustrated in (Table 1). There were no significant differences in the distribution of the stages of ARM between the two subgroups (Table 2), linear by linear association 0.052; $P=0.82$. Advanced ARM (Stage 3) was the predominant stage in both groups: $45.86 \%$ for the drusen only group and $41.94 \%$ for the fellow eye group. Post hoc analysis was conducted to assess whether combining the stages of ARM 0a to $2 \mathrm{~b}$ would improve the power of the sample in identifying a difference between the two subgroups. No significant difference in the distribution was found after

\section{Table 1 Classification of mutually exclusive stages of ARM ${ }^{12}$}

\begin{tabular}{ll}
\hline Stage & Description \\
\hline $0 \mathrm{a}$ & No signs of ARM at all \\
$\mathrm{Ob}$ & Hard drusen $(<63 \mu \mathrm{m})$ only \\
$1 \mathrm{a}$ & Soft distinct drusen $(\geqslant 63 \mu \mathrm{m})$ only \\
$\mathrm{1b}$ & Pigmentary abnormalities only, no soft drusen $(\geqslant 63 \mu \mathrm{m})$ \\
$2 \mathrm{a}$ & Soft indistinct drusen $(\geqslant 125 \mu \mathrm{m})$ or reticular drusen only \\
$2 \mathrm{~b}$ & $\begin{array}{l}\text { Soft distinct drusen }(\geqslant 63 \mu \mathrm{m}) \text { with pigmentary } \\
\text { abnormalities }\end{array}$ \\
3 & $\begin{array}{l}\text { Soft indistinct }(\geqslant 125 \mu \mathrm{m}) \text { or reticular drusen with } \\
\text { pigmentary abnormalities }\end{array}$ \\
4 & Atrophic or neovascular AMD \\
\hline
\end{tabular}
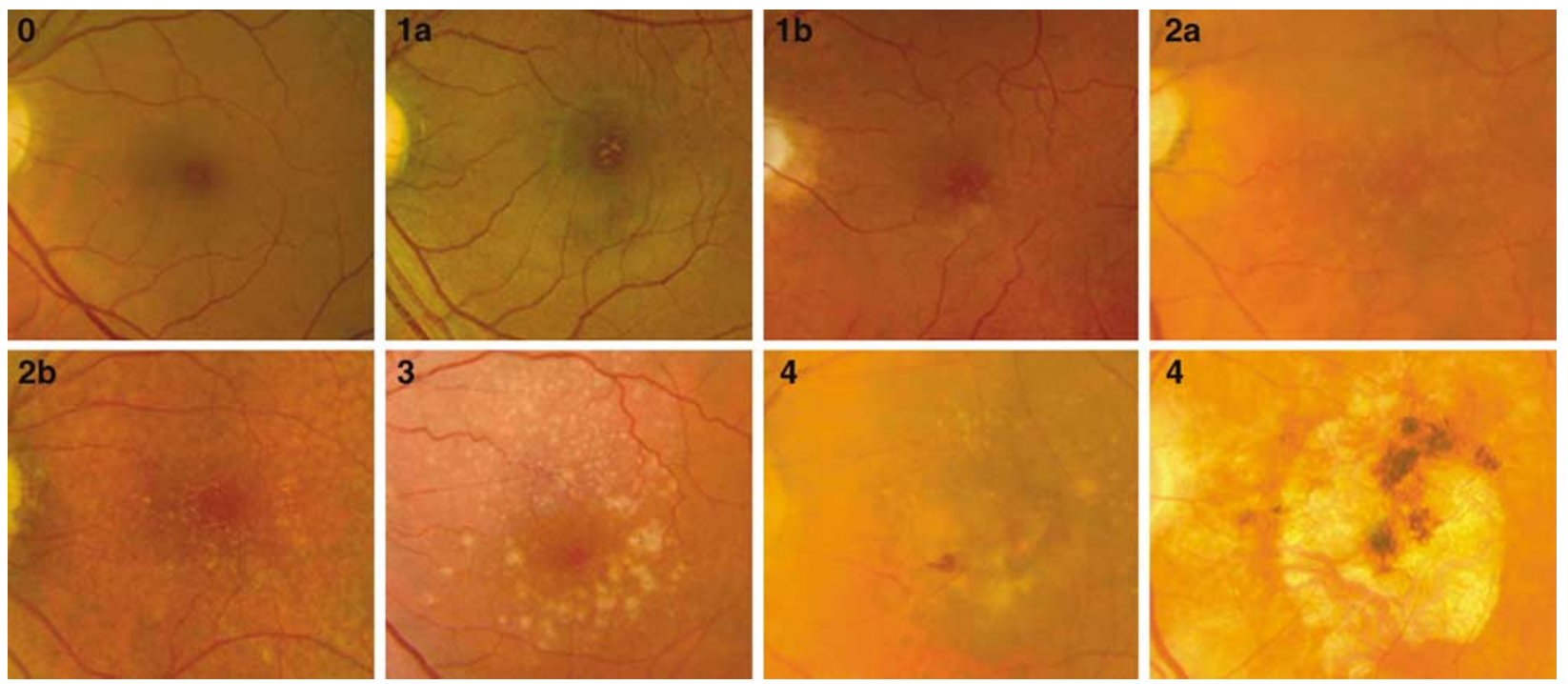

Figure 1 The modified international grading system for ARM. 
Table 2 Distribution of stages in group A (bilateral drusen) and group B (fellow eye of exudative AMD)

\begin{tabular}{lcccc}
\hline Stage & Group A & Percentage & Group B & Percentage \\
\hline $\mathrm{Oa}$ & 1 & 0.75 & 0 & 0 \\
$\mathrm{Ob}$ & 13 & 9.77 & 3 & 9.60 \\
$\mathrm{la}$ & 14 & 10.52 & 5 & 16.13 \\
$\mathrm{lb}$ & 3 & 2.26 & 0 & 0 \\
$\mathrm{2a}$ & 24 & 18.05 & 5 & 16.13 \\
$\mathrm{2b}$ & 17 & 12.78 & 5 & 16.13 \\
3 & 61 & 45.86 & 13 & 41.94 \\
Sum & 133 & & 31 & \\
\hline
\end{tabular}

combined analysis (linear by linear association 0.182 ; $P=0.7)$.

\section{Discussion}

People with unilateral ARM are three times as likely to have early ARM in their second eye when compared with people with no ARM in both eyes. ${ }^{13}$ It is known that the fellow eye of exudative AMD is more likely to develop CNV. Retrospective studies showed that approximately $4-12 \%$ of patients with a CNV in one eye will have a CNV develop in their fellow eye within 1 year. ${ }^{14-17}$ A prospective study reported a $6 \%$ annual rate. ${ }^{18}$ AMD was shown to be bilateral in $57 \%$ of AMD cases. $^{19}$

The absolute risk of AMD can be stratified by stage of early ARM as found in a large population based study. ${ }^{12}$ For subjects with ARM stage 0, the overall risk of AMD within a 5-year period was virtually absent, irrespective of age. For subjects with ARM stage 1, the risk was $0.9 \%$. Subjects with ARM stage 2 had an overall risk of $7.8 \%$, which increased to $28 \%$ for those with ARM stage $3 .^{12}$ It could be expected that a subgroup of patients at high risk of developing $\mathrm{CNV}$ would have predominantly stage 3 ARM. This would make identification of drusen type a useful screening tool. In the Rotterdam study the concept that neovascular AMD develops from stage 2 or 3 has not reached statistical significance. ${ }^{12}$

Our retrospective analysis of patients presenting to a tertiary referral centre suggests that the modified international classification system did not identify any features that could be used as a basis for screening high-risk patients (fellow eye subgroup) from a more heterogeneous group of patients (bilateral drusen subgroup). Our study found that advanced ARM (stage 3 ) is equally prevalent in both patient subgroups studied. One possibility is that patients with mild ARM are less likely to be referred to a tertiary centre and may not be represented in our sample of patients with bilateral drusen. Our study is also limited by the relatively small number of patients in the fellow eye subgroup. Data concerning long-term visual and disease outcome is required to clarify the significance of the distribution of ARM stage in our cohort of patients.

There is increasing evidence that the spatial distribution of drusen is also significant when assessing risk of visual loss in ARM. Holz et $a l^{20}$ found that the degree of confluence of drusen within $1600 \mu \mathrm{m}$ of the centre of the fovea and focal extrafoveal areas of atrophy of the retinal pigment epithelium were significant risk factors.

In a prospective series of 3684 patients followed up over a 10-year period in the Beaver Dam, Wisconsin study, larger drusen found in the inner circle of the Wisconsin template were more likely to have geographic atrophy. Large drusen found in the outer circle was more likely to be associated with persons who did not have advanced AMD. ${ }^{21}$

In summary, there is growing interest in the development of prophylactic intervention for early ARM aiming to prevent CNV formation. A method of identifying high-risk patients from those at lower risk of severe visual loss from $\mathrm{CNV}$ in a population of patients commonly found in a tertiary referral hospital is desirable for this purpose. Type of drusen, as identified by the modified International grading system, may not be reliably predictive in screening for patients who are at high risk of developing $\mathrm{CNV}$.

\section{References}

1 Klaver CC, Wolfs RC, Vingerling JR, Hofman A, de Jong PT. Age-specific prevalence and causes of blindness and visual impairment in an older population: the Rotterdam Study. Arch Ophthalmol 1998; 116(5): 653-658.

2 Klein R, Klein BE, Linton KL. Prevalence of age-related maculopathy. The Beaver Dam Eye Study. Ophthalmology 1992; 99(6): 933-943.

3 Dickinson AJ, Sparrow JM, Duke AM, Thompson JR Gibson JM, Rosenthal AR. Prevalence of age-related maculopathy at two points in time in an elderly British population. Eye 1997; 11(Part 3): 301-314.

4 Owen CG, Fletcher AE, Donoghue M, Rudnicka AR. How big is the burden of visual loss caused by age related macular degeneration in the United Kingdom? $\mathrm{Br} \mathrm{J}$ Ophthalmol 2003; 87(3): 312-317.

5 Yuzawa M, Hagita K, Egawa T, Minato H, Matsui M. Macular lesions predisposing to senile disciform macular degeneration. Jpn J Ophthalmol 1991; 35(1): 87-95.

6 Klein R, Klein BE, Jensen SC, Meuer SM. The five-year incidence and progression of age-related maculopathy: the Beaver Dam Eye Study. Ophthalmology 1997; 104(1): 7-21.

7 Sandberg MA, Weiner A, Miller S, Gaudio AR. High-risk characteristics of fellow eyes of patients with unilateral neovascular age-related macular degeneration. Ophthalmology 1998; 105(3): 441-447.

8 Vingerling JR, Dielemans I, Hofman A, Grobbee DE, Hijmering M, Kramer CF et al. The prevalence of age-related 
maculopathy in the Rotterdam Study. Ophthalmology 1995; 102(2): 205-210

9 Wang JJ, Foran S, Smith W, Mitchell P. Risk of age-related macular degeneration in eyes with macular drusen or hyperpigmentation: the Blue Mountains Eye Study cohort. Arch Ophthalmol 2003; 121(5): 658-663.

10 Bird AC, Bressler NM, Bressler SB, Chisholm IH, Coscas G, Davis MD et al. An international classification and grading system for age-related maculopathy and age-related macular degeneration. The International ARM Epidemiological Study Group. Surv Ophthalmol 1995; 39(5): 367-374.

11 Klaver CC, Assink JJ, van Leeuwen R, Wolfs RC, Vingerling $\mathrm{JR}$, Stijnen $\mathrm{T}$ et al. Incidence and progression rates of agerelated maculopathy: the Rotterdam Study. Invest Ophthalmol Vis Sci 2001; 42(10): 2237-2241.

12 van Leeuwen R, Klaver CC, Vingerling JR, Hofman A, de Jong PT. The risk and natural course of age-related maculopathy: follow-up at $61 / 2$ years in the Rotterdam study. Arch Ophthalmol 2003; 121(4): 519-526.

13 Mukesh BN, Dimitrov PN, Leikin S, Wang JJ, Mitchell P, McCarty CA et al. Five-year incidence of age-related maculopathy: the Visual Impairment Project. Ophthalmology 2004; 111(6): 1176-1182.

14 Gass JD. Drusen and disciform macular detachment and degeneration. Arch Ophthalmol 1973; 90(3): 206-217.
15 Gregor Z, Bird AC, Chisholm IH. Senile disciform macular degeneration in the second eye. Br J Ophthalmol 1977; 61(2): 141-147.

16 Bressler SB, Bressler NM, Fine SL, Hillis A, Murphy RP, Olk $\mathrm{RJ}$ et al. Natural course of choroidal neovascular membranes within the foveal avascular zone in senile macular degeneration. Am J Ophthalmol 1982; 93(2): 157-163.

17 Strahlman ER, Fine SL, Hillis A. The second eye of patients with senile macular degeneration. Arch Ophthalmol 1983; 101(8): 1191-1193.

18 Macular Photocoagulation Study Group. Five-year followup of fellow eyes of patients with age-related macular degeneration and unilateral extrafoveal choroidal neovascularization. Arch Ophthalmol 1993; 111(9): 1189-1199.

19 Wang JJ, Mitchell P, Smith W, Cumming RG. Bilateral involvement by age related maculopathy lesions in a population. Br J Ophthalmol 1998; 82(7): 743-747.

20 Holz FG, Wolfensberger TJ, Piguet B, Gross-Jendroska M, Wells JA, Minassian DC et al. Bilateral macular drusen in age-related macular degeneration. Prognosis and risk factors. Ophthalmology 1994; 101(9): 1522-1528.

21 Knudtson MD, Klein R, Klein BE, Lee KE, Meuer SM, Tomany SC. Location of lesions associated with age-related maculopathy over a 10-year period: the Beaver Dam Eye Study. Invest Ophthalmol Vis Sci 2004; 45(7): 2135-2142. 